\title{
ESTUDOS DE VARIÁVEIS GRÁFICAS NO AUXÍLIO DA CONCEPÇÃO DE IMAGENS INSTRUCIONAIS DE CAMPANHAS DE SAÚDE
}

\author{
Marina Ramires Reynaux Borba \\ Faculdade Boa Viagem | DevryBrasil \\ marinaramires@gmail.com \\ Hans da Nóbrega Waechter \\ Universidade Federal de Pernambuco \\ hnwaechter@terra.com.br
}

\begin{abstract}
Resumo: A presente pesquisa apresenta um estudo sobre o desenvolvimento de imagens instrucionais presentes em materiais gráficos de campanhas de saúde de prevenção e combate à dengue. A pesquisa abordou estudos sobre variáveis gráficas, imagem e campanhas de saúde de combate à dengue com o objetivo de desenvolver um modelo experimental para desenvolvimento adequado de imagens destinadas a esse tipo de artefato educacional, de forma a contribuir para uma correta compreensão da atividade proposta pelos mesmos - cujo intuito é o aprendizado pelo sujeito - e com isso reforçar a necessidade do trabalho de um designer no processo de desenvolvimento desses materiais. Para tal foram propostas soluções gráficas que contribuam para uma melhor identificação do procedimento proposto nesses materiais adequando-os às necessidades informacionais do sujeito.
\end{abstract}

Palavras-chave: variáveis gráficas, campanhas de saúde, modelo experimental

\begin{abstract}
This research presents a study on the development of instructional images in graphic materials for health campaigns to prevent and combat dengue. The study addressed studies on graphic variables, image and health campaigns to combat dengue in order to develop an experimental model for proper development of images to this kind of artifact educational campaigns in order to contribute to a correct understanding of the proposed activity for those who want to understand the content - and with it to strengthen designer's work in the development process of these materials. To meet this objective, graphics solutions have been proposed to contribute to a better identification of the proposed procedure in such materials, suiting the informational needs of the subject.
\end{abstract}

Key-words: Graphics variables, health campaigns, experimental models 


\section{INTRODUÇÃO}

Diferentes métodos de educação são adotados para suprir algumas necessidades comunicativas e instrutivas existentes, principalmente, entre governo e a população, em especial no que diz respeito aos problemas de saúde, que podem ser combatidos com a ação conjunta entre as duas esferas. A educação não formal auxilia nesse processo, pois alcança um público mais amplo, possibilitando um maior êxito no objetivo proposto pela comunicação. As campanhas educativas de saúde fazem parte dessa educação não formal, que transmite informações às pessoas através de diferentes meios, como jornais, revistas, rádio, TV, internet, matérias gráficos entre outros (BERBEL e RIGOLIN, 2011).

As campanhas de cunho educativo costumam utilizar a linguagem gráfica em seus materiais com o objetivo de atingir um número elevado da população à qual se destinam. Schramm (1976) ressalta, em estudos realizados sobre comunicação de massas, que os planejadores de informação de saúde concluíram que as campanhas que utilizam imagens para auxiliar mensagens educativas são mais eficazes, pois alcançam um número maior de destinatários. Convém salientar, entretanto, que a simples inserção de imagens não garante a eficácia da campanha. É importante avaliar o contexto em que a mensagem visual está inserida e os elementos gráficos trabalhados nela para que essa não cause problemas de interpretação e compreensão, pois podem apresentar ambiguidades e complexidades.

As campanhas de prevenção que utilizam a linguagem visual em seu conteúdo constituem um componente importante na proposta oficial de controle das doenças, tanto no esclarecimento da população a respeito do trabalho dos órgãos oficiais de saúde, quanto na ênfase à participação popular e atuação governamental. No Brasil, apesar da existência das campanhas educativas e informacionais de combate e controle da dengue, a permanência da situação endêmica revela problemas no modelo de comunicação, informação e educação em saúde (PITTA, 1995).

Tem-se, portanto, como objeto de estudo a análise das variáveis gráficas que auxiliam na melhor compreensão de imagens instrucionais presentes nos materiais das campanhas de saúde de combate à dengue, apresentando, portanto, subsídios que otimizem a interpretação e a consequente adoção da atividade de prevenção, propondo soluções gráficas que minimizem a falha na comunicação dos materiais de tais campanhas, que influenciam na correta compreensão das imagens por um público diversificado.

Nesse sentido as campanhas se tornam instrumentos de educação para promoção da saúde, passando a ser uma estratégia de controle orientada pelo Estado, com a finalidade de provocar uma mudança de comportamento frente a uma situação endêmica. No entanto, é valido salientar a importância do conhecimento dos sujeitos, suas histórias, valores, crenças, costumes e relações sociais, possibilitando uma troca de conhecimento/informação entre estes e o Governo para contribuir na solução dos problemas em questão.

Deste modo, com base nos estudos da linguagem visual, das campanhas educativas e das variáveis gráficas, foi possível identificar quais as variáveis da linguagem gráfica estão presentes nos meios impressos dessas campanhas e quais 
podem ser trabalhadas nessa comunicação e que são passíveis de manipulação experimental para uma nova proposta comunicativa com maior eficácia.

É dessa forma que o presente estudo poderá vir a sedimentar conhecimentos na linha de investigação do Design da Informação que aborda situações de interesse público - como promoção da saúde pública através da educação -, criando subsídios para o planejamento de materiais gráficos educativos de prevenção e combate de doenças, tornando a prática de atitudes preventivas um hábito.

\section{IMAGENS E CAMPANHAS DE SAÚDE}

A forma de comunicação da sociedade atual tem sido frequentemente mediada pela imagem, e esta é pensada como facilitadora, ao auxiliar na compreensão e interpretação da mensagem. De acordo com Estrella (2006), o termo sociedade da imagem faz referência ao modo como temos nos expressado e percebido as informações, principalmente por meio dos veículos de massa. Ainda segundo a autora, a imagem participa com certa constância da comunicação, porque ela é uma forma visual capaz de organizar narrativas que estão sempre evoluindo e variando com as experiências de cada sociedade.

Essa participação constante da imagem no contexto da sociedade atualmente deve-se à forma universal de como ela pode comunicar. Contudo há diferentes tipos de imagens que entram diariamente no cotidiano das pessoas e podem ser observadas através do cinema, revista, televisão e, mais recentemente, com grande frequência, pela internet. É conveniente enfatizar que nesta pesquisa as imagens que estão sendo referenciadas são as utilizadas em suporte impresso, conhecidas como imagens em duas dimensões, visto que o presente projeto trabalhou com imagens retiradas dos materiais gráficos (folders) das campanhas de saúde de combate à dengue que foram entregues às comunidades da Cidade do Recife entre os anos de 2011 a 2013.

Por ser uma forma simbólica de representar a realidade, é preciso que, para a elaboração e utilização das imagens destes materiais, o ilustrador tenha conhecimento das diferenças culturais e também dos respectivos significados para os elementos visuais nelas trabalhados, pois, dependendo de cada sociedade e do seu contexto histórico, o significado desses elementos pode variar. Gombrich (2007) explica que existem várias formas de se interpretar uma imagem e essa interpretação depende do observador, e a maior dificuldade está em estabelecer como se dão essas mudanças de interpretação, e este é o desafio do designer ao produzir imagens para um público extremamente diversificado.

Portanto, é possível perceber que a utilização de imagens que vêm acompanhando as mensagens nem sempre facilita a comunicação, podendo muitas vezes confundir o leitor sobre o que realmente se quer dizer. Em pesquisa realizada por Coutinho \& Freire (2006), verificou-se que as imagens presentes em livros infantis de língua portuguesa utilizadas para fins pedagógicos não foram identificadas nem compreendidas pela maioria dos estudantes pesquisados, visto que possuíam problemas de qualidade visual, bem como não faziam parte do repertório cultural dos alunos ao qual as mesmas eram destinadas. 
O mesmo foi constatado na pesquisa sobre a compreensão das imagens instrutivas de prevenção e combate à dengue, que verificou que o público pesquisado não conseguiu compreender a instrução presente nas imagens, o que interferia na execução da tarefa proposta, pois apresentavam falhas, tais como: i) o tamanho das imagens em alguns materiais era muito reduzido; ii) cortes na imagem dificultavam a identificação de detalhes; e iii) falta de indicação de uma ação para um melhor entendimento de uma instrução (BORBA, 2013).

Dessa forma é possível observar que algumas mensagens podem ter interpretações errôneas, diferentes do que se quer passar, por alguns motivos: a) falta de dados na mensagem; b) falta de repertório do leitor/espectador/analisador; c) contexto cultural/social diferente da mensagem que se vive; d) algum problema vivido pela pessoa, que dificulta certos níveis de interpretação. Algumas imagens podem ter significados diferentes conforme o contexto em que se inserem, e sua interpretação depende da experiência anterior na qual a percepção estética se encontra. Para não ocorrer alguns desses problemas, no momento da criação de alguma ideia que se queira passar, o importante é fazer um estudo do público-alvo para saber como melhor se encaixa a mensagem, de acordo com interpretação da ideia pretendida.

As imagens contêm sentidos que devem ser lidos e interpretados pelos seus observadores, mas é sabido que mesmo as imagens visíveis de forma imediata e inata nem sempre são compreendidas com facilidade, especialmente se forem distanciadas do seu contexto, seja ele em tempo ou espaço (AUMONT, 2002).

Portanto, ao se criar uma campanha de saúde utilizando imagens instrucionais é necessário um estudo sobre quem será o receptor, e em que contexto histórico e social ele está inserido. As campanhas de saúde de prevenção e combate à dengue, veiculadas em suportes gráficos, têm apresentado certa dificuldade de interpretação por parte dos sujeitos que entram em contato com tais materiais. A forma como as instruções estão representadas tem causado dúvidas de interpretação, e muitas vezes levado o sujeito a ter uma compreensão errônea, tornando, dessa forma, a comunicação falha e sem atingir seu objetivo, que é educar os sujeitos através das instruções contidas nesses materiais (BORBA, 2013). O significado da imagem vai depender da especificidade histórico-cultural na qual está inserida, portanto, a interpretação dessa imagem vai receber a interferência da cultura visual.

No entanto é possível fazer uso de diferentes variáveis gráficas que possam auxiliar na compreensão de uma mensagem que é feita através de imagens pictóricas, sendo necessário, portanto, que o designer, ao produzir um material como os das campanhas de saúde, conheça os recursos gráficos existentes e o público destinatário da mensagem, para então construir uma mensagem que atinja o maior número de sujeitos, efetivando o objetivo principal da campanha - no caso das campanhas da dengue, é a diminuição e tentativa de extinção dos mosquitos e, consequentemente, o número de pessoas infectadas.

\section{ESTUDO DE VARIÁVEIS GRÁFICAS}

As variáveis gráficas são os elementos gráficos presentes nas imagens pictóricas que podem ser modificados objetivando a mensagem e seu conteúdo. Neste tópico 
são apresentados dois modelos analíticos - Evelyn Goldsmith (1984) e Clive Ashwin (1979) - que subsidiaram a seleção das variáveis que foram consideradas e trabalhadas neste estudo, bem como foram, também, estudadas as variáveis propostas por Spinillo (2000), que contemplam a representação de instrução.

Em seu livro Research into illustration: an approach and a review, Evelyn Goldsmith (1984) propôs um modelo analítico de compreensão de ilustrações com o objetivo de estudá-las visando melhorar a identificação, pois muitas vezes a linguagem pictórica pode causar problemas de interpretação da mensagem desejada. Para sua análise a autora parte dos níveis semióticos propostos por Charles Morris (1938 apud GOLDSMITH, 1984), como o sintático, o semântico e o pragmático, e através deles são identificados elementos que possam interferir, positivamente ou não, na identificação e compreensão da mensagem transmitida pela ilustração.

De forma breve, é possível definir os níveis semióticos da seguinte forma: o nível sintático é o reconhecimento dos elementos gráficos sem identificação de significados para a imagem; o nível semântico identifica o conteúdo e significado da imagem, o sentido literal proposto pelo elaborador; o nível pragmático trata da identificação do significado da imagem pelo observador a partir de suas experiências anteriores. No modelo de Goldsmith (1984), utilizado nesta pesquisa, foram traçados quatro fatores visuais que estão relacionados aos níveis semióticos, e considerados para indicação das variáveis desse projeto: unidade - parte reconhecida da imagem pelo observador, mesmo que a identidade da mesma não seja compreendida; locação - relação espacial entre os elementos, ou seja a disposição deles na composição, envolve sobreposição, formas, texturas, etc; ênfase - relação hierárquica das informações visuais, e relaciona-se com a atração e o direcionamento da atenção do observador; e texto paralelo - relação entre a ilustração e texto, que verbaliza a imagem, ou seja, descreve em palavras o que está representado graficamente.

O outro modelo de análise gráfica estudado foi o de Clive Ashwin (1979) que desenvolveu um modelo analítico considerando o conceito de estilo como conteúdo semântico, pois mudanças na sintaxe gráfica resultam em mudanças no significado da imagem, ou seja, antes de se ler uma figura é preciso lê-la como figura.

O modelo, baseado nas funções sintáticas e semânticas das imagens, considera sete variáveis que caracterizam seu estilo e que foram levadas em consideração para proposta de melhorias gráficas: consistência - representação homogênea ou heterogênea da imagem, ou seja, as técnicas de representação utilizadas na elaboração dessas imagens; gama - utilização de várias possibilidades sintáticas da imagem, ou seja, a sintaxe é afetada pela amplitude de efeitos do meio escolhido; enquadramento - disposição da imagem pictórica e seu suporte; posicionamento organização dos componentes da imagem de forma simétrica, quando há um ordem, ou casual, quando há certa aleatoriedade na distribuição; proximidade - escala dos componentes da imagem; cinética e naturalismo.

Diante do teor instrucional das imagens presente neste estudo, é importante abordar e utilizar também os estudos desenvolvidos por Spinillo (1999; 2000) referentes a sequências de representação de procedimentos. Seus estudos foram tomados como base para propor lista com elementos gráficos que facilitam a compreensão das imagens com as devidas adaptações para os fins desta investigação. 
Segundo a autora, existem oito tipos de variáveis de representação gráfica que fazem parte dessa linguagem e, dependendo da forma de apresentação, podem interferir, positiva ou negativamente, na compreensão da mensagem. São elas: apresentação do texto - sugere que o texto relacionado ao conteúdo gráfico se situe o mais próximo possível (e.g. legenda, texto-corrido e/ou rótulo); disposição da sequência pictórica - a forma como estão alinhadas as sequências das imagens pictóricas e dispostas no material gráfico (e.g. horizontal, vertical, oblíqua, circular e ramificada); orientadores de leitura - são utilizados para explicar e facilitar o entendimento da sequência das imagens gráficas, auxiliando a leitura correta da SPP (e.g. números, setas, letras); elementos de separação visual - recursos utilizados para identificar visualmente cada imagem gráfica de forma isolada, possibilitando a delimitação da área da representação (e.g. espaço, linhas, bordas); elementos simbólicos - convenções empregadas que se tornaram representação de algo, podendo indicar negação/proibição ou simbolizar elementos que possivelmente estão presentes no repertório (e.g. setas, barra diagonal); elementos enfáticos - recursos gráficos utilizados para enfatizar elementos específicos, atraindo a atenção do leitor ou indicando um detalhe na imagem (e.g. formas, cores, elementos que chamem a atenção do leitor ou mostrem detalhes da ilustração); estilo da ilustração - forma utilizada para representação das imagens gráficas (e.g. fotográfico, desenho, esquemático, sombra); representação da figura - conteúdo do objeto representado, podendo ser um fragmento do mesmo ou ele por inteiro (e.g. ilustrações parciais e/ou completas).

Diante dos recursos gráficos analisados, observou-se que alguns deles funcionam com certa eficácia na representação de instrução, facilitando a identificação e compreensão da mensagem.

\section{MÉTOdO E ANÁLISE}

Para realização da pesquisa foi feita uma revisão bibliográfica relacionada ao tema. Em seguida foi desenvolvido um modelo experimental a partir de uma nova proposta gráfica para 4 (quatro) imagens (figuras 1,2,3 e 4) coletadas e selecionadas de materiais gráficos das campanhas de prevenção e combate à dengue distribuídos na cidade do Recife entre os anos de 2011 a 2013 com a finalidade de propor soluções gráficas e informacionais que otimizem a compreensão dos artefatos educacionais de campanhas educativas que utilizam imagens instrutivas, de forma que estas campanhas se adequassem a um público tão diverso ao qual são destinadas.

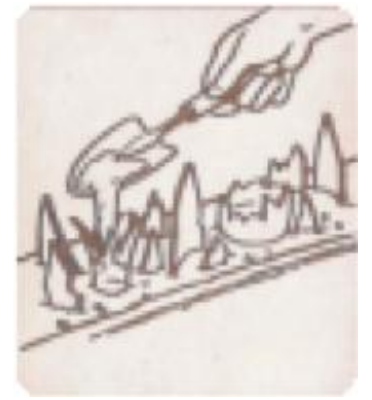

Figura 1 - Representação da instrução de colocar areia nos cacos de vidro. Fonte: Ministério da Saúde, 2011. 


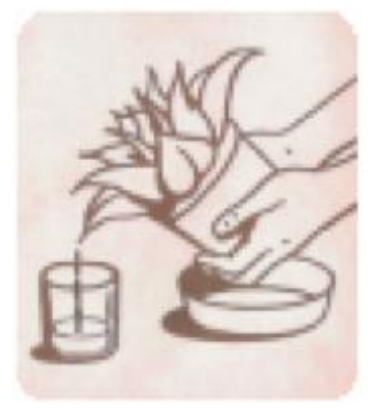

Figura 2 - Representação da instrução de tirar água acumulada das folhas.

Fonte: Ministério da Saúde, 2011.

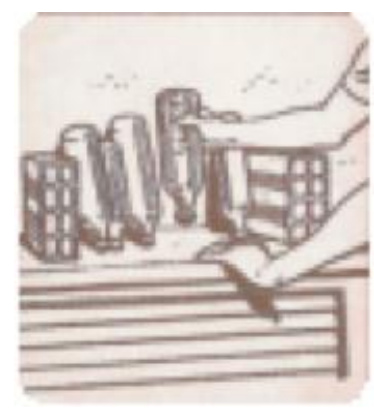

Figura 3 - Representação da instrução de emborcar garrafas.

Fonte: Ministério da Saúde, 2011.

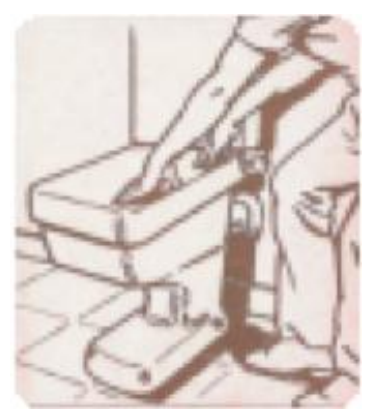

Figura 4 - Representação da instrução de manter tampa do vaso fechada. Fonte: Ministério da Saúde, 2011.

As imagens selecionadas foram avaliadas pelo autor com base nos modelos analíticos de Ashwin (1979), Goldsmith (1984) e Spinillo (1999; 2000) a fim de identificar quais variáveis gráficas presentes nessas imagens e quais delas podem ser manipuladas e quais outras podem ser inseridas para uma melhor identificação e compreensão da ação instrucional proposta por elas. Deste modo foi feita uma relação das variáveis a serem consideradas em um projeto comunicacional como os das campanhas educativas e então foi elaborada, de forma experimental, uma nova proposta das imagens selecionadas com os elementos gráficos considerados eficazes em uma imagem instrucional de fim educativo, e que deve estar presentes no desenvolvimento de campanhas de saúde com o fim de combate e prevenção.

Dentre as imagens selecionadas não foram identificados elementos gráficos de representação de movimento, bem como as imagens não são apresentadas em forma de sequências. A ausência dessas características dificulta a compreensão da imagem 
como instrução/ação, portanto, são elementos que devem estar presentes nas imagens de procedimentos, já que há, de acordo com estudos mostrados por Souza e Lima (2010) e Spinillo (2000), uma maior compreensão das atividades quando esses elementos são inseridos às imagens pictóricas em questão.

Destarte, foram relacionadas as seguintes variáveis para elaboração de imagens instrutivas de campanhas de saúde: representação homogênea, pois as imagens serão elaboradas apenas por uma técnica, a digital; gama restrita, já que as representações serão mais sintetizadas; enquadramento conjuntivo, possibilitando o sujeito perceber em que contexto/ambiente o objeto principal está inserido; presença de indivíduo de forma que facilite na identificação de que a imagem representa uma ação; representação de movimento por símbolos gráficos, auxiliando na direção em que o movimento deve ser feito; sequência pictórica, para mostrar todo o processo do procedimento; cor, para diferenciar os elementos inseridos nas imagens; números, como orientadores de leitura.

Diante das variáveis selecionadas foi proposta uma nova elaboração de imagens (figuras 5, 6, 7 e 8) que representações instruções, no que diz respeito às inseridas em materiais gráficos de campanhas de saúde.
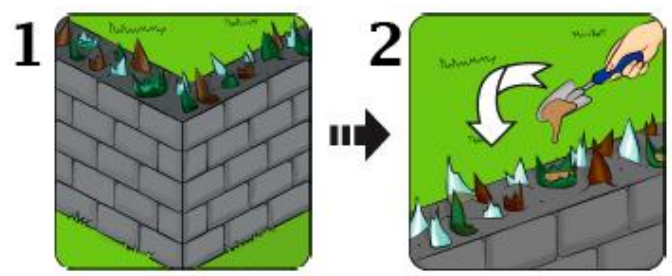

Figura 5 - Reelaboração da instrução, com o uso das variáveis estudadas, de colocar areia nos cacos de vidro.

Fonte: Elaborado pelo autor, com base na pesquisa realizada.
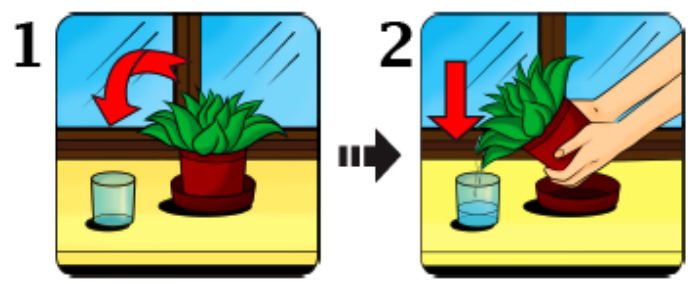

Figura 6 - Reelaboração da instrução, com o uso das variáveis estudadas, de tirar água acumulada das folhas.

Fonte: Elaborado pelo autor, com base na pesquisa realizada.
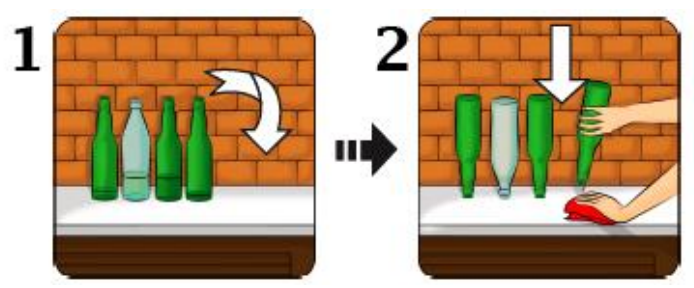

Figura 7 - Reelaboração da instrução, com o uso das variáveis estudadas, de emborcar garrafas. Fonte: Elaborado pelo autor, com base na pesquisa realizada. 


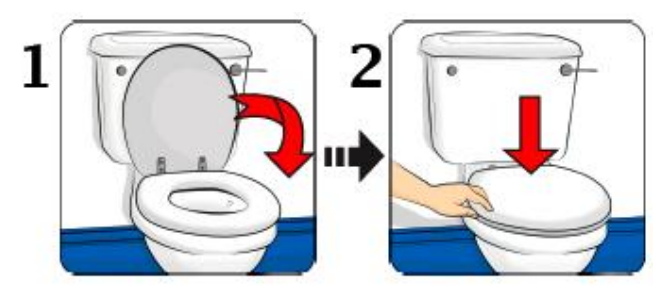

Figura 8 - Reelaboração da instrução, com o uso das variáveis estudadas, de manter tampa do vaso fechada.

Fonte: Elaborado pelo autor, com base na pesquisa realizada.

Os elementos visuais selecionados são explicados por diversos autores como sendo variáveis que tornam a linguagem gráfica mais eficaz. De acordo com Spinillo (2000) o uso de seta como orientador de leitura facilita a visualização correta da ordem das imagens, percebendo uma sequência. Segundo Souza e Lima (2010) o uso de seta inserida na própria imagem facilita a compreensão de uma ação, bem como a direção e origem podem ser identificadas respectivamente, pela ponta e pela cauda, para compreender o início da instrução. Ainda para Arnhein (2005), a percepção de movimento se dá pela representação sucessiva de eventos/objeto, como observado também por Spinillo (2000), que sugere que a percepção da atividade se dá com maior êxito, quando o observador consegue compreender todas as etapas do procedimento, do início ao fim. Por fim, Ashwin (1979) explica que enquadramento disjuntivo é uma variável para destacar o elemento principal, enfatizado-o, facilitando a sua identificação por parte do observador.

As modificações foram efetuadas nas imagens com o intuito de, utilizando o design da informação, melhorar a comunicação permeada pelas representações pictóricas dos procedimentos a serem tomados para prevenir e combater a dengue. 0 objetivo é desenvolver uma proposta visual para que essa comunicação seja mais eficiente, e que assim a população possa participar mais ativamente desse combate, além de mostrar o papel social do design da informação.

\section{CONCLUSÃO}

A complexidade de desenvolver uma comunicação de massa, devido à diversidade do público alvo (SHRAMM, 1970), faz que muitas vezes as campanhas de saúde pública apresentem ambiguidades e dificuldades de compreensão de suas mensagens, principalmente quando elas apresentam um teor persuasivo, sugerindo uma mudança de atitude da população. Para amenizar esse problema, o uso de imagens nos materiais gráficos apresenta-se como um recurso comunicacional mais eficaz para um público deveras diversificado (SPINILLO, 2000). Com esta pesquisa percebeu-se que apenas a inserção desse recurso não era suficiente para alcançar a compreensão da comunicação, pois a elaboração não estava adequada para o público destinado.

Gombrich (2007) sugeriu a importância de se desenvolver uma mensagem visual bem como o conhecimento sobre os destinatários dessa mensagem. Portanto, diante dessas verificações, este estudo mostra não só a importância de se conhecer o 
público-alvo das mensagens no que diz respeitos a sua cultura, costumes e convenções sociais, para conjeturar sobre seu repertório, mas também a importância de um profissional capaz de conhecer as ferramentas e técnicas para elaboração de imagens que sejam apropriadas para uma interpretação correta da mensagem visual.

Fica claro que uma mensagem não funciona só, e pode perder seu valor comunicativo se o contexto é negado - não só o contexto gráfico espacial apropriado, como o ambiente no qual o elemento que deve ser interpretado esteja suprimido.

Com a análise das imagens, foi possível verificar quais os elementos gráficos que poderiam ser trabalhados na elaboração das representações de procedimentos. Foram selecionados elementos que, a princípio, fazem parte do repertório do público das campanhas e tendem a facilitar o reconhecimento e compreensão da mensagem visual. A partir da análise dos resultados é possível então propor diretrizes para o uso de imagens em material educativo e ambiental que facilite sua compreensão, a seguir são listadas algumas considerações para o desenvolvimento e uso de imagens em tais materiais:

- setas - por se tratarem de imagens que indicam aos sujeitos ações/procedimentos a serem realizados o uso desse recurso facilitou o entendimento de conteúdo dinâmico e as setas substituem alguns verbos (e.g. fechar e abrir) dos procedimentos representados;

- SPPs - a representação da ação feita através do uso de imagens sequenciadas mostrou que facilitou na identificação dos passos da tarefa que os sujeitos deveria realizar, pois com esse recurso torna-se possível a identificação do início e do término do procedimento;

- cores - esse recurso torna mais clara a diferença de cada objeto representado bem como facilita na identificação de profundidade diferenciando cada elemento tornando mais fácil a percepção da ação.

Para a produção das imagens pictóricas que serão inseridas nesses materiais conta-se com o auxílio do designer da informação, que possui conhecimentos para eleger os critérios que farão parte da construção dos materiais. Esses profissionais devem escolher o meio em que as imagens pictóricas serão inseridas, bem como a seleção do conceito que deve ser seguido. Para atingir esses objetivos, Mijksenaar e Westendorp (1999) traçam alguns questionamentos que devem ser respondidos durante o processo de construção desses materiais, tais como: $O$ que será explicado nas imagens? Que imagens serão utilizadas? Como será recebida a mensagem pelos sujeitos? Entre outras, que fazem parte dessa construção.

Portanto, é possível verificar a importância do papel das instruções visuais, já que são um conjunto de informações sobre o procedimento de tarefas relacionadas a diversas áreas, como lazer, saúde, segurança, comprovando a sua importância na sociedade. A realização de determinadas tarefas depende, muitas vezes, das informações visuais contidas no material instrucional.

Finalmente, esta pesquisa objetivou colaborar com as discussões acerca do design da informação de cunho social, contribuindo com melhorias nas construções visuais relativas a esses temas. 


\section{REFERÊNCIAS}

ARNHEIM, Rudolf. Arte e percepção visual: uma psicologia da visão criadora. Trad. Ivonne Terezinha de Faria. São Paulo: Pioneira thomson Learning, 2005.

ASHWIN, Clive. The ingredients of style in contemporary illustration: a case study. Information Design Journal, n. 1, p. 51-67. 1979.

AUMONT, Jacques. A Imagem. Trad. Estela dos Santos Abreu. São Paulo: Papirus, 2002.

BERBEL, Danilo B., RIGOLIN, Camila C. Educação e promoção da saúde no Brasil através de campanhas públicas. Revista Brasileira de Ciência, Tecnologia e Sociedade, v.2, n.1, p.25-38, jan/jun 2011.

BORBA, Marina Ramires Reynaux. Comunicação e instrução: a linguagem visual das campanhas de saúde de combate à dengue. 2013. 151 fl. Dissertação (mestrado) Universidade Federal de Pernambuco, Curso de Pós-Graduação em Design. 2013.

COUTINHO, Solange \& FREIRE, Verônica. Design para Educação: uma avaliação do uso da imagem nos livros infantis de Língua Portuguesa. In: 150 Encontro Nacional da ANPAP - arte: limites e contaminações. Salvador: ANPAP. No.1 /2 | Vol. 3 - 2006.

ESTRELLA, Chamberlly. Comunicação e Imagem. Rio de Janeiro: Editora Rio, 2006.

GOLDSMITH, Evelyn. Research into Illustration: An Approach and a Review. Cambridge University, 1984.

GOMBRICH, Ernst Hans. Arte e Ilusão: um estudo da psicologia da representação pictórica. 4a ed. São Paulo: WMF Martins Fontes, 2007.

MIJKSENAAR, Paul, WESTENDORP, Piet. Open here: the art of instructional design Joost Elffers Books, 1999.

PITTA, A. M.; OLIVEIRA, V. C. Estratégias de comunicação frente ao desafio do Aedes aegypti no Brasil. Ciência \& Saúde Coletiva, [s. I.], v. 1, n. 1, p. 137-146, 1995.

SCHRAMM, Wilbur. Comunicação de massa e desenvolvimento. Trad. Muniz Sodré e Roberto Lent. 2. Ed. Rio de Janeiro: Bloch Editores, 1976.

SCHRAMM, Wilbur, RIVERS, William. Responsabilidade na comunicação de massa. Trad. Muniz Sodré e Roberto Lent. Rio de Janeiro: Bloch Editores, 1970.

SPINILLO, C. G. Instruções visuais: algumas considerações e diretrizes para sequências pictóricas de procedimentos. Estudos em Design, Rio de Janeiro, v. 9, n. 3, p. 31-50, 1999.

SPINILLO, C. G. An analytical approach to procedural pictorial sequences. Tese (Doutorado em Tipografia e Comunicação Gráfica)- Department of Typography \& Graphic Communication, The University of Reading. 2000.

SOUZA, José Marconi Bezerra; LIMA, Ricardo Cunha. O design de gráficos auxiliares na representação de movimento para fins instrucionais. In: 9o Congresso Brasileiro de Pesquisa e Desenvolvimento em Design. 2010. 